\title{
Medium Absorption Reticulocytes to Total Reticulocytes Ratio Measurement
}

National Cancer Institute

\section{Source}

National Cancer Institute. Medium Absorption Reticulocytes to Total Reticulocytes Ratio Measurement. NCI Thesaurus. Code C116193.

The determination of the ratio of medium absorption reticulocytes compared to total reticulocytes present in a sample. The measurement may be expressed as a ratio or percentage. 